\title{
A constituição da faculdade de educação/UFRGS em tempos de ditadura militar (1970 - 1985)
}

\section{Resumo}

A pesquisa busca aproximações das memórias de uma instituição de ensino superior, a Faculdade de Educação/UFRGS. Procura compreender como, no presente, os sujeitos professores rememoram o tempo vivido naquela instituição, investigando as marcas que ela deixou. Interessam os significados atribuídos pelos narradores às suas vivências na Faculdade e os modos como compõem suas reminiscências. $O$ estudo insere-se no campo de investigações da História da Educação, sendo esta uma componente da história das práticas culturais e do cotidiano social, e identifica-se com os pressupostos teóricos da História Cultural. A metodologia fundamenta-se na História Oral, trabalhando-se as narrativas de memória como documento. Ao longo das entrevistas com professores, os quarenta anos da Faculdade de Educação foram rememorados de três temas principais que emergiram nas narrativas: as greves das décadas de 1980 e 1990, a importância da Faculdade como espaço de constituição da identidade docente e, entre os mais antigos servidores, as lembranças da época da ditadura militar vividas no cenário da Universidade, temática que aqui nos propomos a analisar. Portanto, neste estudo, refletimos acerca das implicações da ditadura militar na constituição e no cotidiano da Faculdade da Educação, nos anos 1970 e início dos anos 1980, investigando os processos identitários da Faculdade de Educação que se constitui enquanto importante espaço de formação docente no Rio Grande do Sul. Tomamos como fontes da pesquisa entrevistas realizadas com docentes da FACED, entrevistas publicadas em periódicos e um documentário produzido por ocasião dos trinta e cinco anos da Faculdade de Educação.

Palavras-chave: Memórias docentes. História da educação.

História das instituições educativas.

\section{Doris Bittencourt Almeida}

Doutora em Educação pela

Universidade Federal do Rio Grande do Sul (UFRGS). Professora de

história da educação da Faculdade de Educação (FACED/UFRGS)

almeida.doris@gmail.com

Valeska Alessandra de Lima

Acadêmica do Curso de Pedagogia da Universidade Federal do Rio Grande do Sul. Bolsista FAPERGS akelacharruas@yahoo.com.br

Thaise Mazzei da Silva

Acadêmica do Curso de História da Universidade Federal do Rio Grande do Sul. Bolsista CNPq. isemazzei@hotmail.com

\section{Para citar este artigo:}

ALMEIDA, Doris Bittencourt; LIMA, Valeska Alessandra de; SILVA, Thaise Mazzei da. A constituição da faculdade de educação/UFRGS em tempos de ditadura militar (1970-1985). Revista Tempo e Argumento, Florianópolis, v. 5, n.10, jul./dez. 2013. p. 317-346.

\section{DOI: $10.5965 / 2175180305102013317$}

http://dx.doi.org/10.5965/2175180305102013317 


\title{
The constitution of the education college / UFRGS in times of military dictatorship (1970 - 1985)
}

\begin{abstract}
The research look for approaches of the memories of an institution of higher education, The Education College / UFRGS. Try to understand how, in present time, the teachers remind the time lived in that institution, investigating the marks that it left. . Interest the meanings ascribed by the narrators to their experiences at the College and the ways in composing their reminiscences. The study is part of the field investigations in the History of Education, which is a component of the history of cultural practices and everyday social, and identifies with the theoretical assumptions of Cultural History. The methodology is based on oral history, working up the memory as a document. Throughout the interviews with the teachers the forty years of The Education College were remembered from three main themes that emerged from narratives. : the strikes of the 1980 s and 1990s, the importance of the College as a place of formation of teacher identity, and among older workers, the memories from times of military dictatorship lived in the University scenario, a theme that we propose here to analyze. Therefore, in this study, we reflect about the implications of military dictatorship in the constitution and in everyday Education College in the 1970 s and early 1980s, investigating the identity processes at The Education College as an area that is important teaching training in Rio Grande do Sul. . We take as sources of research interviews with teachers from FACED, interviews published in periodicals and a documentary produced on the occasion of the thirty-five years of The Faculty of Education.
\end{abstract}

Keywords: Teachers memories. History of education. History of educational institutions. 
Há muito tempo que ando Nas ruas de um Porto não muito alegre Que no entanto me traz encantos E um pôr de sol me traduz em versos (...) (Osvaldir e Carlos Magrão, Horizontes)

\section{Memórias e Histórias da Faculdade de Educação.}

A História da Educação no Brasil ainda guarda muitos silêncios, entre eles estudos sobre instituições de ensino e memórias de seus atores educativos. E comprometidos com essa discussão nos propusemos a desenvolver a pesquisa "Memórias e Histórias da FACED (1970-2010)" que tem como objetivo geral iniciar a produção de histórias da Faculdade de Educação da Universidade Federal do Rio Grande do Sul (FACED/UFRGS), dando ênfase, ao lado de outros documentos, às trajetórias dos sujeitos que partilharam desse importante espaço de formação docente no Estado. Para além da construção da história da instituição, a investigação está especialmente interessada nos sentidos e significados atribuídos pelos informantes às suas diferentes experiências na FACED, nos modos como compõem suas reminiscências, nas lembranças e nos esquecimentos que ativamente construíram quando instados e provocados por evocadores de memórias, a narrá-las nos eventos das entrevistas.

Antigos servidores e alunos carregam as memórias da instituição e dos processos pelos quais historicamente passou a educação em âmbito nacional e regional, o que justifica entrevistá-los evitando, assim, o apagamento das práticas educativas relativas a um tempo e a um lugar. O propósito da pesquisa é no sentido de articular e promover interconexões entre as histórias vividas, fomentando reflexões sobre as condições materiais nas quais se produziram determinados processos educativos.

A investigação se insere no campo da História da Educação e identifica-se com os pressupostos teóricos da História Cultural. Se História e História da Educação estão muito próximas uma da outra, se é difícil estabelecer suas fronteiras, é preciso estreitar esses diálogos e isso passa por uma discussão acerca da História Cultural, como tendência 

Cultural, rejeita a história política factual, renuncia às certezas e racionalidades que davam o tom da historiografia dos séculos XIX e parte do século XX. Ao invés de um tempo de certezas absolutas, postula-se a restauração da dúvida como princípio do conhecimento e a pluralidade de respostas para o âmbito de resultados obtidos, instaurou a "era da dúvida, da suspeição, pondo em causa a coerência do mundo." (PESAVENTO, 2003, p. 16). Isso não quer dizer que se caia no relativismo absoluto, mas que se admita que as coisas não precisam ser isto ou aquilo. Revela-se uma postura na qual é possível entender não só a ambiguidade/ambivalência dos fenômenos sociais, mas também a linguagem metafórica e simbólica empregada nos discursos.

Cunha (1999, p. 41) analisa a fecundidade das relações entre História Cultural e História da Educação por promover um alargamento das possibilidades investigativas, indo muito além dos aspectos mais formais da educação, em "direção a outros campos do conhecimento, sujeitos e objetos até então inexplorados.”. Como dizem Lopes e Galvão (2010), a pesquisa em História da Educação nunca foi tão "imaginativa e inovadora, o campo de pesquisa torna-se "multifacetado e pluridisciplinar" (2010, p. 427). Esse “território plural” (LOPES e GALVÃO, 2010) aproxima-se do que Pesavento (2003, p.15) diz: "o olhar de Clio mudou e voltou-se para outras questões e problemas, para outros campos e temas.". Neste sentido, passam a ocupar espaço novos atores sociais, práticas e sentidos da História. Os sujeitos até então excluídos/esquecidos pela História da Educação não foram vidas de silêncio, mas, sim, vidas relegadas ao silêncio, que não encontraram uma escuta sensível e que passaram despercebidas pelo tempo. A História, agora, busca construir uma trama, tendo como personagens aqueles e aquelas “(...) sobre cujo silêncio foi construída a história" (RANCIÈRE, 1995, p. 54).

Essas referências são importantes para aguçar o nosso olhar para as histórias da Faculdade de Educação da UFRGS. Entende-se a Faculdade como espaço de múltiplas aprendizagens, um microcosmo social que funciona como espaço de maturação intelectual, não somente um lugar de aprendizagens de saberes, mas, ao mesmo tempo, 

pesquisas desenvolvidas são testemunhos preciosos de épocas e espaços significativos para a História da Educação.

Os trabalhos com memórias e, especialmente, com narrativas, por meio da metodologia da História Oral, oferecem uma dimensão singular para nos relacionarmos com o tempo vivido. Os encontros com informantes, quando se busca capturar instantes de memórias, podem se constituir em momentos de fecundidade das relações humanas. Conversar com esses docentes da FACED, perceber como se movimentam no prédio procurando antigos lugares, buscando colegas que talvez já nem estejam mais nos antigos postos, escutá-los, observá-los, ler seus escritos, olhar fotografias que comumente trazem para as entrevistas são momentos em que podemos nos acercar das marcas de um outro tempo. A emoção e o sentido de humanidade promovidos pela História Oral (Prins, 1992) calam fundo nas pesquisadoras, que encontram em tal metodologia de pesquisa novas formas de compreensão do passado, formas com as quais se identificam.

As narrativas de memória constituem o corpus empírico da investigação, sendo, portanto, a História Oral o caminho para a produção dessa fonte. Michel Pollak (1992) destaca que a construção coletiva e social da memória está submetida a transformações e mudanças constantes e que a memória se constitui pelas pessoas, lugares e acontecimentos vividos pessoalmente ou herdados do grupo ou coletividade ao qual se pertence. Há que se considerar, deste modo, a complexidade do trabalho com memórias, sua relatividade e subjetividade, tanto quanto sua capacidade de constituir-se como documentação histórica.

Foram vários os questionamentos que a priori se apresentaram aos sujeitos envolvidos na pesquisa. Quem são eles? Que lugares de sujeito ocuparam ao longo dos anos de trabalho na Faculdade? Como desenvolveram seu ofício? Quais as circunstâncias históricas vividas na FACED que perpassaram suas vidas? Que aspectos foram preponderantes em suas trajetórias? Em que medida assimilaram os discursos 

ou seja, o critério fundamental foi ter muitos anos de vivência na Faculdade. Baseados em um mapeamento inicial, decidimos nos debruçar sobre cada entrevista e analisá-las uma a uma, suas singularidades, aquilo que foi dito, aquilo que não foi dito, tentando levantar hipóteses do por que foi dito, buscando recorrências entre elas e possíveis dissonâncias. São muitos anos, quarenta para alguns, ou seja, todo o tempo de existência da Faculdade, vividos naquele espaço e, de repente, no evento da entrevista, alguns fragmentos deste tempo vêm à tona, emergem das camadas mais profundas da memória e tornam-se lembranças. São esses (Quadro 1) os sujeitos da pesquisa.

Quadro 1 - Entrevistas Memórias e Histórias da FACED

\begin{tabular}{|c|c|}
\hline $\begin{array}{c}\text { Entrevistas } \\
\text { Individuais }\end{array}$ & $\begin{array}{c}\text { Tempo de vínculo com a } \\
\text { Faculdade }\end{array}$ \\
\hline Jacarandá & 38 anos \\
\hline Paineira & 30 anos \\
\hline Palmeira & 38 anos \\
\hline Ipê Amarelo & 33 anos \\
\hline Grevilha & 40 anos \\
\hline Tipuana & 20 anos \\
\hline Cinamomo & 42 anos \\
\hline Figueira & 40 anos \\
\hline Cipreste & 30 anos \\
\hline Ipê Roxo & 30 anos \\
\hline Ébano Oriental & 30 anos \\
\hline Flamboyant & 10 anos \\
\hline Mimo de Vênus & 15 anos \\
\hline Canafístula & 40 anos \\
\hline
\end{tabular}




\begin{tabular}{|c|c|}
\hline $\begin{array}{c}\text { Roda de Memória } \\
\mathbf{2 0 1 1}\end{array}$ & 35 anos \\
\hline Araucária & 30 anos \\
\hline Timbaúva & 30 anos \\
\hline Ligustro & 20 anos \\
\hline Pitangueira & 35 anos \\
\hline Guapuruvu & \\
\hline
\end{tabular}

Fonte: Arquivo FACED

Cada entrevistado ${ }^{1}$ é componente de um amálgama maior que é sua coletividade. Foi desta maneira que cada um falou acerca dos significados da Faculdade de Educação em suas vidas, relembrou o cotidiano, os encantamentos, alegrias, tristezas, frustrações vividos na FACED. Importa dizer que ao retornar ao passado, cada um pode evocar lembranças com perspectivas distintas, afinal os sujeitos se transformam, passam por diferentes experiências ao longo do tempo. É a subjetividade de cada um que indica o que é importante e o que não é importante lembrar. Segundo Viñao-Frago (2000, p.11), "la misma historia cambia cuando es contada por diferentes protagonistas u observadores. Cada una de ellos, com su parte de verdad, nos ofrece aspectos que los otros silencian u ocultan". Então, considerando a parcela de verdade que cada um traz ao evocar o passado, aqui procuramos analisar as narrativas no contexto de sua produção.

Ao longo das entrevistas com os professores, os quarenta anos da Faculdade de Educação foram rememorados em três temas principais que emergiram nas narrativas: as greves das décadas de 1980 e 1990, a importância da Faculdade como espaço de constituição da identidade docente e, entre os mais antigos servidores, as lembranças da época da ditadura militar vividas no cenário da Universidade, temática que aqui nos propomos a analisar.

\footnotetext{
1 Diante da manifestação de alguns entrevistados que não autorizaram a divulgação de seus nomes, decidimos preservar a todos, atribuindo pseudônimos para identificá-los. A inspiração para a escolha de árvores como pseudônimos dos sujeitos da pesquisa se deve ao fato de o prédio da FACED, bem como todo o Campus Central da UFRGS, ser rodeado de árvores. Consideramos também as que existem no Parque Farroupilha, que se localiza ao lado do Campus Central.
} 
Portanto, neste estudo, refletiremos acerca das implicações da ditadura militar na constituição e no cotidiano da Faculdade da Educação, nos anos 1970 e início dos anos 1980. Tomamos como fontes de pesquisa quatorze entrevistas e uma roda de memórias ${ }^{2}$ realizadas com docentes da FACED, escritos dos professores e entrevistas publicadas em periódicos como a Revista Educação e Realidade ${ }^{3}$ e o Jornal da Universidade 4 . Além disso, analisou-se e transcreveu-se o documentário "Condor", no qual professores da Faculdade de Educação da UFRGS e convidados lembram fatos relacionados à ditadura militar.

A Faculdade de Educação da UFRGS tem um passado que se entrelaça à história da comunidade porto-alegrense. Em 2010 comemorou seus quarenta anos. Porém, qual o marco escolhido para definir o ano um de sua história? E se tomarmos a criação do Curso de Pedagogia como início? Os documentos oficiais da Universidade apontam que o Curso existe desde 1942, na então denominada Faculdade de Educação Ciências e Letras da Universidade de Porto Alegre. Em 1947, a Universidade de Porto Alegre se transformou em Universidade do Rio Grande do Sul, em 1950 passou a fazer parte do sistema federal e em 1970 assumiu a sigla UFRGS. Nesse mesmo ano, por força da chamada Reforma Universitária $(\mathrm{RU})^{5}$, a Universidade Federal do Rio Grande do Sul organizou-se em institutos e faculdades, estrutura que mantém até hoje. Com base nessa reestruturação, ocorreu a criação da Faculdade de Educação, oriunda da Faculdade de Filosofia, ocupando o mesmo prédio que o Colégio de Aplicação ${ }^{6}$, no Campus Central da UFRGS.

A constituição da FACED está atrelada ao desmembramento da antiga Faculdade de Filosofia, que teve sua origem marcada pela tentativa do Governo Federal de

\footnotetext{
${ }^{2}$ As entrevistas foram realizadas em 2010, 2011 e 2012 e a Roda de Memórias em 2011.

${ }^{3}$ Revista Educação \& Realidade - Periódico em Educação que reúne artigos de diferentes aportes teóricos com temas ligados a vários campos do conhecimento - FACED/UFRGS - Porto Alegre/RS.

${ }^{4}$ O Jornal da Universidade é uma publicação mensal da Secretaria de Comunicação da UFRGS - Porto Alegre/RS.

${ }^{5}$ Decreto-Lei 5.540 de 1968.

${ }^{6}$ O Colégio de Aplicação da UFRGS foi criado em 1954 como escola-laboratório vinculado à Faculdade de Filosofia. A partir de 1970, ano de fundação da FACED, as relações entre Colégio de Aplicação e Faculdade de Educação estreitaram-se, pois ambas as unidades passaram a dividir o mesmo espaço físico. O Colégio de Aplicação destacou-se pelo pioneirismo no trabalho educativo, ao propor, por exemplo, classes experimentais, conselhos de classe participativos, projetos interdisciplinares, entre outros. Na década de 1990, o Colégio conquistou sua sede própria localizada no Campus do Vale da UFRGS. (www.cap.ufrgs)
} 
desarticular os focos de resistência à Ditadura Militar em fins dos anos 1960. O esfacelamento da antiga Filosofia deu origem, além da Faculdade de Educação, a outras quatro Unidades: o Instituto de Filosofia e Ciências Humanas, a Faculdade de Biblioteconomia e Comunicação, o Instituto de Letras e o Instituto de Biociências. O surgimento dessas novas Unidades foi parte da Reforma Universitária iniciada em 1968 e trazia consigo a proposta de ampliação de vagas no ensino superior e atendia, desse modo, a uma das reivindicações da classe média da época. ${ }^{7}$

O prédio da Faculdade de Educação (Figura 1), de concepção arquitetônica arrojada, foi erguido na década de 1960, diferenciando-se das demais construções da UFRGS do século XIX e da primeira metade do século XX. Localizado ao lado do Parque Farroupilha, com vista para o Lago Guaíba, em meio ao Centro Histórico de Porto Alegre, está a imponente edificação, em formato retangular em seus nove andares e muitas janelas que Ihe conferem leveza. Atualmente, ocupado pela Faculdade de Educação, suscita muitas recordações. Dentre elas, é possível destacar outra versão para sua construção, quando houve um movimento da Universidade para evitar que a Avenida Loureiro da Silva passasse no meio do Campus Central em direção ao Túnel da Conceição. Conforme Doll; Comerlato, (2010, p.6) esta obra "implicaria na derrubada do antigo prédio da Química, sendo, portanto, a construção da FACED vista como uma forma de resistência à destruição de um patrimônio público". Esta fala nos faz pensar nos entrelaçamentos da história do prédio com as transformações vividas pela cidade naquele tempo.

\footnotetext{
${ }^{7}$ A Faculdade de Filosofia não existe mais, Jornal Zero Hora, Porto Alegre, manchete da capa de 04/04/1971.
} 
Figura 1 - Prédio da Faculdade de Educação em construção

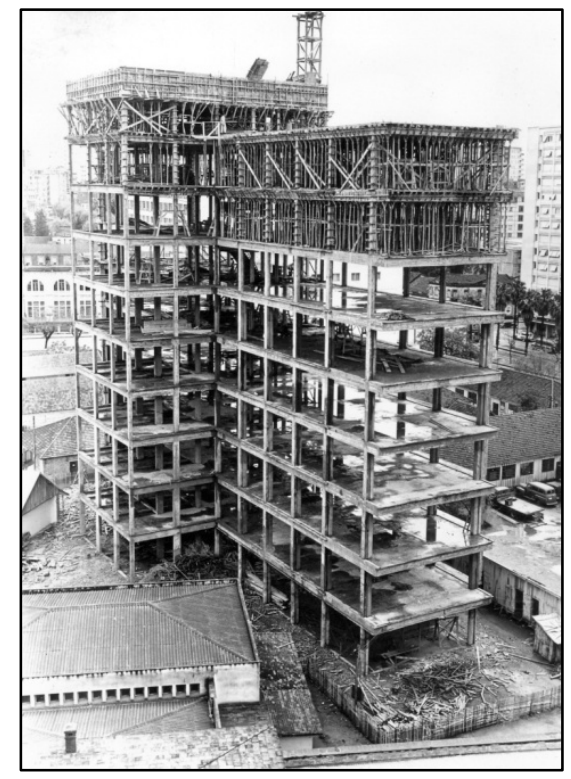

Fonte: Museu da UFRGS
Figura 2 - Prédio da Faculdade de Educação, pronto.

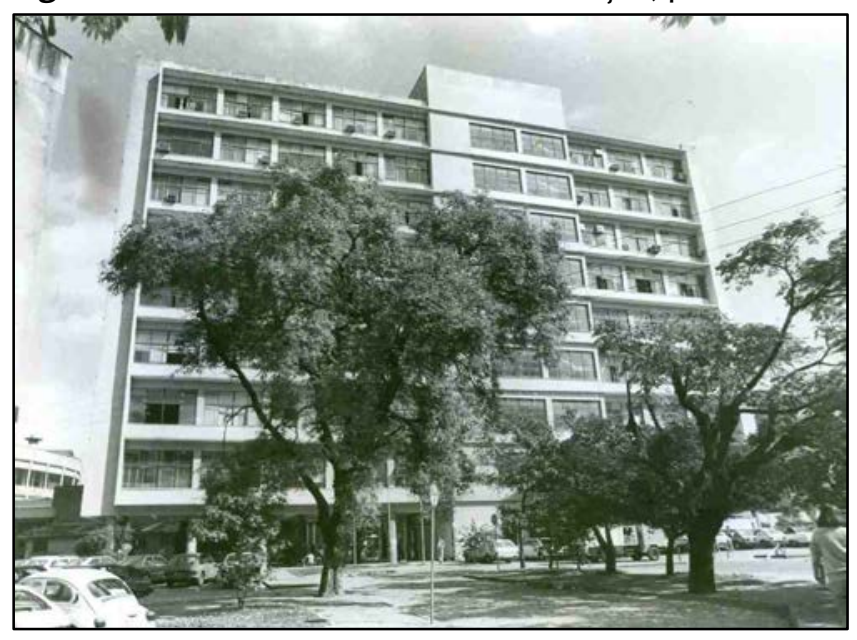

Fonte: Museu da UFRGS

Logo após a criação da Faculdade de Educação como unidade, houve a instalação do Curso de Mestrado em Educação (1974) e do Curso de Doutorado em Ciências Humanas.

\section{Os anos da Ditadura e a Faculdade de Educação: interfaces}

As décadas de 1960 a 1980 foram marcadas por ditaduras na América Latina, em uma sucessão de golpes que fizeram presidentes eleitos serem depostos por militares com o apoio de civis. Em relação ao Brasil, podemos dizer que a Doutrina de Segurança Nacional (DSN) ${ }^{8}$ e a Escola Superior de Guerra (ESG) ${ }^{9}$, legitimaram muitas das ações desses governos, além de originarem o Serviço Nacional de Informação (SNI) que visava

\footnotetext{
${ }^{8}$ A Doutrina de Segurança Nacional foi um conjunto de preposições que definia a existência de fronteiras ideológicas e de inimigos internos (comunistas). Estas ideias foram disseminadas pela Escola do Panamá, organização mantida pelos Estados Unidos da América, para onde militares da América Latina eram enviados.

${ }^{9}$ A Escola Superior de Guerra foi criada na década de 1950, foi por intermédio dela que a DSN ganhou conhecimento Nacional. Entre seus formandos estavam vários apoiadores da tentativa de golpe em 1962 e do golpe em 1964.
} 

apoiadores. Num contexto da Guerra Fria, os países da América Latina eram considerados zona de influência do capitalismo, e por isso deveriam ficar a salvo da interferência nefasta do comunismo da URSS ${ }^{10}$.

No início dos anos da ditadura militar brasileira, algumas transformações para educação nacional estavam sendo pensadas. Para que essas mudanças ocorressem de forma gradual, foram assinados os acordos MEC-USAID ${ }^{11}$ que visavam 0 “aperfeiçoamento" (COSTA, 2009, p.27) do ensino em todas as suas modalidades. Esta reforma tinha o objetivo de padronização do ensino, com base no modelo norteamericano, com a justificativa de que a educação brasileira era tão subdesenvolvida quanto a economia do país. Tais mudanças foram orientadas por estudiosos estadunidenses e pessoas de confiança do governo vigente ${ }^{12}$ que alegavam ser a educação o fator principal para o desenvolvimento do país.

Entre as ações dos acordos estavam: a fusão dos cursos primário e ginásio aliada à supressão de um ano de estudos, originando o antigo primeiro grau de ensino; a diminuição da carga horária de disciplinas como História e a eliminação de outras, como Filosofia. De acordo com Fávero (2006, p.30), havia três linhas de atuação da United States Agency for Internacional Development (USAID) em toda a América Latina: "assistência técnica, financeira e militar". Para iniciar a implantação de novas teorias e metodologias no ensino brasileiro, docentes mais capacitados foram trazidos de fora do Brasil, assim como, os professores nacionais foram enviados aos EUA para aprimoramento profissional. Conforme Marcio Alves (1968) nos mostra em seu estudo,

\footnotetext{
${ }^{10}$ Sobre o contexto dos países da América Latina durante a Guerra Fria consultar: RODEGHERO; GUAZZELLI; DIENSTMANN (2013)

${ }^{11}$ A sigla representa a interação entre o Ministério da Educação e Cultura e a Usaid States Agency for Internacional Development, uma agência do Governo Federal dos Estados Unidos da América que é responsável por programas de ajuda econômica e humanitária em âmbito mundial. A USAID ainda atua em programas de desenvolvimento sustentável no Brasil.

${ }^{12}$ Os estudos e pareceres desenvolvidos neste período foram orientados por generais escolhidos pelos presidentes e também por estudiosos estadunidenses.
} 

governo.

Juntamente com os acordos MEC-USAID, o Ministério da Educação (MEC) solicitou ao Governo Federal dois estudos sobre a educação. De acordo com Costa, o primeiro, denominado Plano Atcon, foi desenvolvido pelo consultor americano Rudolf Atcon que escreveu o livro “Rumo à reformulação estrutural da universidade brasileira” (COSTA, 2009, p. 31). Neste livro, o autor indicava pontos fracos das universidades nacionais e fazia algumas recomendações para sua melhor funcionalidade. O segundo estudo realizado veio por meio de um decreto, do então presidente Costa e Silva, elegia uma comissão que tinha como presidente o General Carlos Meira Mattos e visava emitir pareceres acerca das atividades estudantis, além de planejar, propor e coordenar as diretrizes governamentais no setor estudantil (COSTA, 2009). Como no Plano Atcon, o relatório Meira Mattos, também identificou os pontos que deveriam ser revistos ou modificados nas estruturas educacionais do país.

Com base nestes dois relatórios, em 1968, a Reforma Universitária, foi implantada buscando atender as necessidades da educação brasileira de acordo com os indicativos presentes nos estudos desenvolvidos. O Decreto-Lei apresentava a necessidade de ajustar o funcionamento das instituições de ensino superior conforme o modelo de desenvolvimento econômico. Propunha, entre outras medidas, a extinção da cátedra, o regime de dedicação exclusiva, a carreira docente elaborada segundo os graus e títulos acadêmicos, a instalação de departamentos como unidades administrativas, o sistema de créditos e a indissociabilidade entre ensino/pesquisa. Essas orientações, especialmente a última citada, apresentavam as intenções norte-americanas e encaminhavam a institucionalização da pós-graduação no Brasil ${ }^{13}$.

Neste contexto, em 1970, as diretrizes da Faculdade de Educação da UFRGS foram estabelecidas de acordo com a normatização da Reforma Universitária. Sua divisão

\footnotetext{
${ }^{13}$ A Reforma Universitária visava também à instalação do departamento como unidade administrativa; e o sistema de créditos.
} 
administrativa previa a existência de três departamentos: Departamento de Estudos Básicos (DEBAS); Departamento de Ensino e Currículo (DEC) e Departamento de Estudos Especializados $(D E E)^{14}$, que possuíam uma atuação ampla nas diversas disciplinas do Curso de Pedagogia e nas licenciaturas. Ainda hoje, a Faculdade de Educação mantém os mesmos departamentos da época dos governos militares, fato este que levou os professores Balduino Andreola e Merion Bordas a questioná-los:

A estrutura dos departamentos em nossa Faculdade tem ainda algum sentido? Se a resposta for positiva, não caberia discutir se a composição atual ainda se justifica? Muita coisa mudou. Novas áreas de conhecimento e de ação passaram a ser priorizadas, sem que tenham o devido suporte na estrutura atual de nossos três departamentos. Muitas coisas importantes aconteceram ou estão acontecendo em nossa Faculdade, através de grupos interdisciplinares e interdepartamentais. Se os departamentos desaparecessem ou se recompusessem, o que aconteceria, de positivo ou de negativo? Qual é, afinal, a identidade dos nossos departamentos? Administrativamente, não estariam superados, como um anacronismo da reforma de 1968? Como áreas de conhecimento, não poderiam ser comparados a uma pensão, que abriga disciplinas as mais diversas, sem apresentar uma definição e uma unidade sob os ângulos epistemológico e político? (BORDAS; ANDREOLA, 2010, p.301)

De acordo com um dos entrevistados, a Reforma Universitária previa que os professores contratados pudessem lecionar qualquer disciplina que pertencesse ao seu departamento, mesmo que o docente não possuísse formação e conhecimentos teóricos e metodológicos para a tal cadeira.

[...] essa chefe de departamento [...] me chamou e disse: Tu vais dar Psicologia da Educação. Eu disse: Como? Eu sou concursado de História da Educação. [Ela] Não "tá" faltando professor de psicologia. Então de acordo com esse modelo de universidade do MEC-USAID, o professor lotado num departamento pode, por direito dar qualquer disciplina do departamento, isso é pra demolir uma universidade, impressionante [...]. (entrevista com Canafístula, 2012).

\footnotetext{
${ }^{14}$ DEBAS - Aprendizagem em Ambientes Digitais, Educação Especial/Inclusão Escolar, Filosofia da Educação, História da Educação, Psicologia da Educação e Sociologia da Educação; DEE - Política e Administração da Educação, Educação Infantil, Educação de Jovens e Adultos, Psicopedagogia e Tecnologia em Educação; DEC - Ensino (Didática, Estágio) e Currículo (Teorias do Currículo, Organização Curricular, Planejamento e Avaliação, Ensino e Identidade Docente, Educação Contemporânea).
} 
A questão da extinção do cargo de professor catedrático, o qual era o responsável por uma área específica de conhecimento e possuía assistentes que trabalhavam sob sua direção, é lembrada de forma positiva por uma docente:

A Reforma Universitária [...] derruba com a cátedra, deixando de ter o professor catedrático. Eu acho que esse foi um momento muito importante, [...] a universidade, um espaço de todos e de todos os professores já que com a cátedra havia uma relação muito forte de dominação, de autoridade e de autoritarismo do catedrático não só o que ensinar e como ensinar, inclusive na escolha dos professores, eles convidavam as pessoas para se tornar professores da universidade. (entrevista com Grevilha, 2010)

Diante do fim da cátedra, a proposta era que organização de teorias e metodologias passasse a ser debatida entre todos os professores do departamento. Porém, pode-se se dizer que essa discussão se dava muito mais na teoria do que na prática, tendo em vista todo controle exercido sobre as opiniões e as ideias durante o período da ditadura. Disso tudo, permanece uma indagação: qual seria a intenção da RU ao extinguir a cátedra? Podemos pensar que, eliminando o poder do professor catedrático, o governo suprimisse possíveis interferências de pessoas que talvez fossem consideradas perigosas para o regime da época.

Com a Reforma Universitária limitando os movimentos dentro das instituições de ensino superior, os projetos e práticas pedagógicas ficavam enquadrados dentro dos moldes projetados pela ditadura para a educação brasileira. Desse modo, o Curso de Pedagogia da UFRGS foi estruturado em cinco habilitações: administração escolar, inspeção escolar, supervisão escolar, orientação educacional e matérias pedagógicas da habilitação do Magistério. Porém, nenhuma delas era pensada para atender as questões próprias da docência. Formavam-se professores que não trabalhariam em sala de aula, preparavam-se verdadeiros técnicos que saberiam resolver situações de ordem administrativa, legitimando o distanciamento da realidade escolar daquelas que cursavam a graduação em Pedagogia. Um entrevistado reforça as críticas a esse padrão elitista de formação docente e avalia os prejuízos, ao dizer que 
[...] o DEE, era Departamento de estudos especializados que formava os denominados especialistas em educação e eram tão especialistas em educação que eram formados para nunca estar em sala de aula. Eram os supervisores, os coordenadores, os administradores e o pior de tudo, os inspetores. (entrevista com Palmeira, 2011)

Enquanto a Faculdade de Educação se constituía como unidade da Universidade e a insegurança da ditadura militar assolava o Brasil, mudanças significativas para a política, economia e educação estavam sendo tramadas. De um lado, a Lei de Segurança Nacional, em suas diversas reformulações ${ }^{15}$, definia os crimes políticos e de opinião além de legalizar a expulsão de qualquer cidadão do país que pudesse infringir algum mal ao Estado. De outro, estabeleceu-se o fechamento de instituições que pudessem ter ligações diretas ou indiretas com ações consideradas subversivas. Isso servia como forma de controlar as ações dos estudantes que, em 1964, com a Lei Suplicy de Lacerda (4.464/64), viraram alvo da repressão e tiveram extinguida a União Nacional dos Estudantes (UNE), o que colocava diversos centros acadêmicos na clandestinidade. Com este tipo de medida, o governo desenvolveu meios de se fazer presente nas instituições de ensino e se promoveu um clima de desconfiança, em que professores, alunos e funcionários estavam atentos àquilo que falavam e para quem falavam, pois a vigilância dos serviços ligados à ditadura era constante. Foram promovidas cassações de professores, confisco de teses e livros considerados contrários à ideologia da época e havia até mesmo intromissões de pessoas ligadas ao SNI dentro das salas de aula que promoviam constrangimentos, provocando o medo generalizado.

Essas lembranças foram sistematicamente evocadas ao longo das entrevistas e aqui são tematizadas no intuito de perceber as interfaces entre os anos de ditadura e a constituição da FACED. Há que se considerar que no documento oral, trabalha-se com a narrativa que é permeada pela imaginação e da subjetividade. A fala é suscetível às vicissitudes de cada momento, todavia, não significa que a memória seja intangível, pelo contrário, permite a aproximação de verdades que se quer produzir sobre o vivido. E

\footnotetext{
${ }^{15}$ A primeira Lei de Segurança Nacional foi criada em 1935, onde definia os crimes militares e contra o Estado. Após a Lei de 1935, foram reformuladas outras nos anos de 1953, 67, 69, 78 e 1983, sendo que esta última ainda está em vigor, porém com algumas modificações do seu texto original.
} 

depoente escolhe para contar sua história.

Especialmente aqueles que estavam na Faculdade nos anos 1970 e 1980 não escaparam de trazer à tona reflexões acerca do impacto dos governos militares no cotidiano das salas de aula da Faculdade. A começar pela instalação da Faculdade, Bordas e Andreola dizem que

A FACED foi criada, em 1970, num modelo que não tinha nada a ver com a história anterior, sendo uma aplicação da Reforma Universitária de 1968, feita sob o Regime Militar. Tratou-se de uma criação que não era esperada naquele momento, uma reforma já pronta, no clima autoritário do Regime Militar. (BORDAS; ANDREOLA, 2010, p.300)

Nas entrevistas, os professores fizeram referência ao lugar onde ficava um setor do SNI, conhecido como o gabinete do coronel. Dois gabinetes, um do reitor, outro de um coronel, dois comandos em tempos de ausência de democracia. Neste sentido, falaram dos primeiros diretores das faculdades que eram de fato interventores, pois suas nomeações precisavam passar pelo crivo da autorização dos militares.

Então, o controle dentro da UFRGS, de acordo com os entrevistados, era encabeçado pelo Coronel Natalício da Cruz Correa que chefiava a Assessoria de Segurança e Informações da UFRGS (ASI/UFRGS). Sua sala localizava-se ao lado do Departamento Pessoal e, conforme Mansan (2009), era a única em todo o quinto andar da Reitoria que não possuía placa indicativa. De acordo com a pesquisa de Mansan, a ASI/UFRGS foi criada em 1968 e, em 1969, ocorreu a nomeação deste militar que, em tese, deveria assessorar o Centro de Processamento de Dados quanto à aquisição de computadores para a universidade.

Podemos imaginar que a relação deste coronel com os professores fosse bastante controversa, pois, ao mesmo tempo em que alguns falam "tinham coisas que tu não podia fazer sem consultar o assessor de segurança da UFRGS, o Cel. Natalício ${ }^{16 ”}$

\footnotetext{
${ }^{16}$ Professor Roberto Facchin
} 
(Brunetto, 2008), outros dizem "ele era muito acessível [e] não te criava muitos problemas" (entrevista com Cinamomo, 2012). Talvez esse exemplo demonstre as contradições próprias da época em que se vivia, enquanto para alguns a presença de um militar na Universidade intimidava, incomodava, para outros era algo naturalizado diante da situação política de exceção que se vivia no país.

A presença do Departamento de Ordem Política e Social (DOPS) dentro da universidade é outro dado anunciado nas entrevistas. O DOPS foi criado para manter o controle e vigiar as manifestações políticas durante a ditadura militar e perseguia, sobretudo, as atividades intelectuais. Professores e professoras discorreram sobre a atuação dos agentes do SNI dentro das salas de aula e nos corredores das faculdades.

[...] os primeiros anos da faculdade de educação foram muito terríveis. Sabendo, inclusive, que havia professores envolvidos com o esquema de informações, colegas que até ocupavam chefia no departamento, então realmente a gente se sentia muito mal, a gente tinha que filtrar, filtrar. A gente entrava na Faculdade de Educação a uma da tarde prá começar a aula a uma e meia e tinha um personagem lá todo vestido de preto lendo jornal, prá controlar o movimento e todo mundo sabia a função dele, inclusive ele assistia aula, estava matriculado. A coisa corria assim, é que as informações podiam ser dadas por qualquer cidadão $[\ldots]^{17}$. (BRUNETTO, 2008)

[...] Bom, daí tava na aula a noite, daí no intervalo [...] um aluno lá no fundo da sala se levantou e veio rápido pra frente [...], pegou o meu livro que tava na mesa e botou assim, professor te cuida que o meu vizinho é agente do DOPS. Daí, depois eu prestei atenção nele, era um cara que era mais velho do que eu, professor, bem mais velho. Daí eu acompanhei ele, chegava perto durante os exercícios de aula, ele escrevia assim, pra vocês terem uma ideia (rabiscando sobre o caderno). Analfabeto, daí eu disse, eu dando aula no ciclo básico numa universidade, e ele não tem a mínima ideia do que eu tô falando, ele não sabia o que acontecia na aula, não sabia nada e era recrutado pra dar informação [...]. (entrevista com Palmeira, 2012).

Essas falas indicam a presença de olheiros que se instalavam sorrateiramente nas salas de aula. Segundo Merion Bordas "tínhamos alunos de todos os cursos e as turmas eram grandes. Era um lugar propício para aparecerem os observadores" (2010, p.302). Em entrevista ao Jornal da Universidade, em 2009, a professora conta que,

\footnotetext{
${ }^{17}$ Professor Fernando Becker
} 
[...] Quando dava aula de didática, em 1972, nunca sabíamos quem eram os alunos, cada dia era um. Era uma disciplina para todos os cursos. E como eu nunca fui muito cautelosa, um dia, quando saí da aula, tinha um rapaz me esperando: "Queria Ihe dizer uma coisa, a senhora fala demais. Gosto da senhora, mas eu sou do DOPS, e se a senhora continuar falando, vou ter que dizer". "Bom, eu agradeço", respondi, "tá bom, então vou tentar maneirar [...]”. (UFRGS, 2009, on line).

Para quem não viveu essa época, tais narrativas parecem carregadas de certa ficcionalidade e sabemos que isso é próprio do processo de memória. Mas fazendo um exercício de alteridade, pode-se tentar se colocar no lugar desses docentes e imaginar o cuidado que deveriam ter em suas falas corriqueiras, o temor de revelarem seus sentimentos e pensamentos. E podemos indagar, o que abordariam em suas aulas que não os ameaçasse?

Sobre os autores proibidos, uns recordaram da ausência, outros da clandestinidade das leituras de Paulo Freire nas aulas da Faculdade de Educação. Uma professora, quase num lamento de culpa, disse que naquela época nem sabia quem era este autor.

O professor, a quem chamamos de Araucária, foi um dos que mais ocupou o tempo da entrevista falando sobre os anos da ditatura na Universidade.

(...) meu nome não era dos mais indicados na área de segurança nacional, porque eu havia sido preso em 69 então havia coisas a meu respeito que certamente estavam dificultando a contratação. Aí eu procurei o Coronel Natalício que era o responsável pela área de segurança aqui na universidade, isso a juventude hoje nem imagina que acontecia dentro da universidade, mas tinha um gabinete no $7^{\circ}$ andar, próximo ao gabinete do reitor, então antes do gabinete do reitor ficava exatamente essa sala do Cel. Natalício. (...) mas quero dizer que a contratação dependeu de uma decisão que não foi acadêmica, não foi da universidade e foi de segurança nacional. (entrevista com Araucária, 2011)

Esse mesmo professor recordou as dificuldades que teve ao encaminhar a tese à Itália, aonde fez seu doutorado.

[A] tese de doutorado saiu da gráfica na manhã do Al-5 [...] o ato máximo da ditadura, o mais atroz [...] na manhã da sexta-feira treze eu encostei uma Kombi lá na gráfica e carreguei meus duzentos exemplares [...]. No 
fim da manhã saiu o Al-5. Da minha tese foi vendido só um exemplar e já foram atrás dos outros [...] pra prender. Eu levei a minha tese de Natal ao Rio de Janeiro por terra pelo interior. E no Rio eu despachei, [...] consegui mandar os 50 exemplares pra Roma e ter o título de doutor [...] esse foi um período complicado nos anos sessenta. (entrevista com Araucária, 2011)

Essas e outras situações provocavam inseguranças entre docentes e discentes, sendo que até mesmo as nomeações de professores concursados eram atravessadas por questões políticas. Araucária também comenta o momento em que foi ao gabinete do Cel. Natalício para saber informações sobre a sua contratação.

[...] Eu disse, "o senhor sabe muito bem que eu fiz concurso e minha contratação não tá saindo, é porque deve ter alguma acusação contra mim". Ele me olhou e disse: "o senhor tem ideia de que acusação pode ser?" Eu me lembro que eu disse, é, no mínimo é porque eu pertencia a um grupo de 11 e eu quero dizer pro senhor que é pura mentira, o grupo era de 18. Aí ele caiu na risada, ficamos rindo por mais um tempo e depois ele disse "quando sair sua contratação, por favor, volte aqui". [...]. (entrevista com Araucária, 2011).

Porém, não somente o ensino superior era alvo dessa repressão constante. 0 Colégio de Aplicação da UFRGS também sofreu com os atos da ditadura militar brasileira.

[...] essa conjuntura ainda da ditadura, da cassação de professores aqui na UFRGS, e mesmo no Colégio de Aplicação logo que eu comecei isso também foi importante, nós tínhamos que cuidar bastante a questão do que trabalhar ... os nossos planos, autores que podiam ser lidos outros não... a participação dos alunos aqui nesse contexto todo que era um contexto bem político né, então tinha que preservar os alunos e aos mesmo tempo eles ficavam sabendo.... eram participantes." (entrevista com Guapuruvu, 2011)

Estas e outras arbitrariedades foram cometidas durante este período de exceção tão conturbado da História do Brasil. Os desaparecidos e mortos desta época ainda hoje são lembrados em diversas ocasiões, pois são signos que lembram um momento que não se quer reviver. As marcas deixadas desse tempo são profundas, e em alguns casos, ainda causam muita dor e comoção. Mesmo as mudanças positivas que ocorrem no campo da educação, não diminuem o sofrimento dos anos de chumbo vividos pela sociedade brasileira. 


\section{A FACED e a ampliação para o Pós-Graduação}

Mudanças no cenário educacional vinham sendo traçadas durante as décadas de 1950 e 1960, por exemplo, com a implantação da Campanha Nacional de Aperfeiçoamento de Pessoal de Nível Superior, criada em 1951, pelo Decreto n 29.741. A Campanha objetivava assegurar que houvesse pessoal especializado para atender às necessidades do setor público e privado, como forma de atingir os ideais de desenvolvimento do país. Em 1964, a Campanha congregou diversos programas e comissões do Ministério da Educação e Cultura e sua denominação foi alterada para Coordenação de Aperfeiçoamento de Pessoal de Nível Superior (CAPES).

Por iniciativa do Ministério da Educação e Cultura, foi assinado o Parecer n 977/65 CFE que definiu os cursos de pós-graduação, tendo como base o modelo de universidade norte-americano. Este Parecer designava o termo lato sensu como os cursos de aperfeiçoamento e especialização, realizados logo após a graduação, com objetivo técnico profissional específico que não conferiam grau acadêmico ao concluinte. Já, o termo stricto sensu definia o ciclo de cursos regulares sequenciais à graduação, o mestrado e doutorado, que visavam desenvolver e aprofundar a formação, conferindo grau acadêmico ao final de cada ciclo. A CAPES passou, a desempenhar papel fundamental para a expansão e consolidação da pós-graduação stricto sensu no Brasil, além de fomentar a pesquisa.

O Parecer 977/65 deixa claro que os cursos de pós-graduação serviriam para desenvolver profissionais de "alto nível", diferenciando-se dos profissionais "comuns" formados na graduação. Assim, a formação passou a ser vista como crucial para alcançar os mesmos patamares dos "países modelo". Para isso, era necessário que as universidades se transformassem em instituições de pesquisa. $E$,

[...] para assegurar a criação de programas de pós-graduação, foi determinado que os professores assistentes deveriam ter o grau de mestre e os adjuntos o de doutor. Esta nova ênfase na pesquisa e na titulação formal provocou uma rápida proliferação dos programas de pós-graduação nas universidades brasileiras. (VERHINE, 2008, p.168) 
Neste período de mudanças para a educação, o Curso de Pós-Graduação em Educação (CPGEDU), um dos primeiros cursos de pós-graduação da UFRGS, foi estruturado na Faculdade de Educação. Para um entrevistado "o momento nacional era crucial porque o governo estava querendo incentivar a pós-graduação e nós não podíamos deixar de estar presentes, [...] pois nós tínhamos condições de competir [...].” (entrevista com Cinamomo, 2012).

Em todo o país, os cursos de mestrado e doutorado foram se expandindo e ganhando destaque. Porém, devido ao reduzido número de professores brasileiros com a formação exigida para ministrar as aulas em nível de pós-graduação e orientar a realização de dissertações e teses, professores norte-americanos assumiram esta função. Vários informantes comentaram as interferências norte-americanas tecnicistas, notadamente com relação à implantação do Programa de Pós-Graduação em Educação, com a presença de professores estadunidenses que foram os primeiros doutores orientadores do Programa. Bordas e Andreola (2010, p.304) afirmam que "o curso foi montado dentro do modelo extremamente norte-americano. Nossos primeiros professores, com raríssimas exceções, vieram dos Estados Unidos". Sob a influência da USAID, docentes estrangeiros foram encaminhados às universidades, gerando certo desconforto entre aqueles que acreditavam ser desnecessário trazer pessoal de fora do país para formar professores em nível de pós-graduação. Merion Bordas, uma das professoras mais antigas da FACED, lembra que foi

[...] aluna da primeira turma, formada quase só de professores do Colégio [de Aplicação] e da Faculdade, sendo somente duas, se bem lembro, as pessoas estranhas. Nós éramos uma turma pequena. Esse curso foi montado dentro do modelo extremamente norte-americano. Nossos primeiros professores, com raríssimas exceções, vieram dos Estados Unidos. (BORDAS; ANDREOLA, 2010, p.304)

Percebe-se na fala de outra entrevistada, o quanto foi afetada pelas interferências externas na formação oferecida pelo Pós-Graduação em Educação da UFRGS.

Outro fato que, me parece, abalou muito quem estava dentro da Faculdade de Educação foi então o surgimento dos cursos de pósgraduação no Brasil e a exigência de que pelo menos os professores tivessem os cursos de pós-graduação. Professores que já estavam aqui 
com a sua produção [...] qualificada dentro das circunstâncias que elas foram realizadas. Eles foram de certa forma, descredenciados dessa qualificação porque eles não tinham pós-graduação e [...] deslocados de patamar, e vem uma pessoa de fora [...]. Faltou aos implantadores uma certa sensibilidade, uma sensibilidade com as pessoas de tentar legitimar ou ajudá-las a se legitimar diante das novas exigências de legislação. (entrevista com Grevilha, 2010)

Interessante notar a narrativa de um dos professores que concluiu seu mestrado no Curso de Pós-Graduação em Educação da FACED, em 1977, e faz questão de valorizar seu orientador norte-americano, argumentando que ele se diferenciava das tendências tecnicistas vigentes. Em suas palavras, “o meu orientador foi o professor Ray Chesterfield, eu o escolhi, não porque era americano, porque eu não vivo de amores pelos Estados Unidos, mas porque era um antropólogo, profundamente respeitoso da nossa cultura[...]" (entrevista com Palmeira, 2011). Também comentou que esse antropólogo foi o orientador de doutorado de Nilton Fischer, professor referência da Faculdade de Educação, conhecido por suas lutas em favor da educação popular.

Diante de tantos conflitos, o Curso de Mestrado em Educação foi implantado em 1972, com três áreas de concentração: ensino, planejamento educacional e psicologia educacional, sendo reconhecido pelo MEC em $1974^{18}$. Pouco depois, ampliou-se com o Doutorado em Ciências Humanas ${ }^{19}$ - Educação, com área de concentração em processos de ensino-aprendizagem, em 1976. Dez anos após a instalação do Doutorado, o CPGEDU passou a denominar-se Programa de Pós-Graduação em Educação (PPGEDU), nomenclatura ainda utilizada.

Desde então, o PPGEDU/UFRGS tem uma valiosa contribuição para a qualificação de inúmeros profissionais e para a pesquisa. Hoje, podemos dizer que o Programa tem uma experiência consolidada no país que atingiu o reconhecimento da comunidade científica em nível nacional e internacional.

\footnotetext{
${ }^{18}$ Parecer n 657/74 do Conselho Federal de Educação.

${ }^{19}$ Parecer 181/82 Conselho Federal de Educação.
} 
Anos 1980: novos tempos na FACED

Sessenta e quatro, sessenta e seis,

Sessenta e oito um mau tempo talvez

Anos 70 não deu pra ti

E nos oitenta eu não vou me perder por aí (...)

(Osvaldir e Carlos Magrão, Horizontes)

Diante da proximidade do fim dos governos militares, sobreveio o período da redemocratização no Brasil, com o paulatino retorno da liberdade de expressão em seus múltiplos aspectos. Respiravam-se novos ares e isso abria espaço para transformações sociais vividas também na Faculdade de Educação.

Até o início da década de 1980, o Curso de Pedagogia não havia sido reformulado e mantinha o mesmo padrão de formação da década anterior. Porém, estas habilitações estavam cada vez mais longe de atender às particularidades e relevâncias próprias da docência. Professores e alunas começaram uma luta por mudanças.

O novo momento vivido no Brasil exigia "formar professores para trabalhar onde está a maioria da população e onde há problemas" (entrevista com Flamboyant, 2012). Neste processo, reformularam-se currículos e estágios. As antigas habilitações foram substituídas, em 1983, pelas habilitações em pedagogia pré-escolar e séries iniciais, manteve-se a habilitação magistério.

A UFRGS era tida como Universidade "da elite para a elite" (entrevista com Mimode-vênus, 2012). Então, os estágios eram realizados dentro do próprio Colégio de Aplicação que ocupava alguns andares do prédio da Faculdade de Educação. Muito cômodo, as futuras pedagogas apenas precisavam descer alguns degraus para realizarem suas práticas, entretanto o comodismo provocava um distanciamento dos significados da escola pública, as graduandas em Pedagogia se limitavam a uma realidade de ensino circunscrita ao Campus Central da Universidade, faltava a essas alunas um envolvimento maior com a sociedade. De acordo com Flamboyant (entrevista, 2012), na década de 1980 “o curso começou a botar o pé no barro, até então era um curso mais elitista”.

Talvez essas novas habilitações e as fronteiras que se abriram com os estágios, 
conformista, é isto, é a melhor palavra para descrever”. Figueira (entrevista, 2012) também avalia que "em 1984 foi a virada na formação oferecida na FACED, começou-se a discutir muito os rumos do Curso de Pedagogia".

Quem viveu a década de 1980 na FACED, não esquece da urgência que havia em exercitar constantemente a democracia, era preciso "botar pra fora os sentimentos. Nós tínhamos inventado que quarta-feira era o dia da comunidade se reunir. Ali o que eu acho que tinha de maior valor é o exercício de ouvir o outro" (entrevista com Flamboyant, 2012).

Nesse contexto, importa destacar o Projeto Periferia do Campus (PERICAMPUS) que abriu as portas da FACED, e a expandiu para além dos muros do Campus Central. O Projeto foi iniciado a pedido da Assessoria Educacional do município de Viamão, que buscava auxílio para as escolas da cidade, o que veio a convergir com a tomada de consciência do caráter social que a Universidade deveria ter. Entre os objetivos centrais do projeto estavam:

interagir com comunidades de vilas populares apoiando-as em seu processo de conscientização com vistas ao auto-desenvolvimento através de ações participativas, nas áreas de educação formal e nãoformal; experimentar novas metodologias de ensino mais adequadas às características sócio-econômica-culturais das comunidades e às necessidades dos profissionais formados pela Universidade; realizar pesquisas em diferentes áreas e abordagens metodológicas que favoreçam a criação e o desenvolvimento de conhecimentos socialmente significativos e de uma consciência crítica da realidade. (UFRGS, 1986, p. 13)

Juntamente com outros cursos da Universidade ${ }^{20}$ a Faculdade de Educação, com seus alunos e professores foi se inserindo nessas comunidades de periferia para ajudar, tanto os alunos quanto os próprios professores. Foram feitas reformulações curriculares, aulas monitoradas, e as relações entre os professores e os alunos revistas. Para os

\footnotetext{
${ }^{20}$ Dentre os cursos que participaram do Projeto estão: Medicina, Enfermagem, Letras, Biblioteconomia, Ciências Sociais, História, Educação Física, Psicologia.
} 
integrantes do Projeto, ele vinha para ajudar as escolas públicas que "parece trabalhar muito mais contra do que a favor do aluno" (UFRGS, 1986, p. 08). Flamboyant (entrevista, 2012) fala que "o projeto PERICAMPUS era um grande espaço para quem queria fazer a experiência com educação popular, essa era a FACED”.

Outro grande movimento dentro da Universidade, e que marca muito a FACED dos anos 1980, são os movimentos grevistas, muitos deles motivados pelos docentes da Faculdade. Com o final dos governos militares, assistiu-se no Brasil um processo de sucateamento do ensino público. Servidores das Universidades Federais mobilizaram-se para reivindicar novos concursos, melhores salários e planos de carreiras, entre outros. Assim, as greves dos professores das Universidades Federais emergiram no cenário dos anos 1980. Este tema foi recorrente nas narrativas de memória, os entrevistados foram interpelados por lembranças das constantes greves, e suas falas indicam que estes períodos de paralisações foram momentos de afirmação da profissão docente, tempos de discussões e de tomadas de posições.

Nas entrevistas, muitos destacaram o papel protagonista assumido pela FACED no contexto da UFRGS, disseram que estar em greve não significava estar em casa, descansando, esperando que a situação se resolvesse à sua revelia, estar em greve assumia o sentido de estar na luta, estar na FACED, ocupando aquele espaço como grevistas, buscando legitimar o movimento. Uma professora avalia o tempo das greves:

[...] então eu fiz o concurso em 84. O concurso foi atrasado porque a Universidade tava em greve em 84 . [...] nós tivemos situações bonitas, [...] os movimentos de greves foram movimentos bonitos, bonitos no sentido de organização, de como nós nos colocávamos entre pares, nas discussões, as próprias polêmicas vividas entre nós, isso foram momentos bonitos. Momentos que mobilizaram nossos alunos a lotar uma sala de aula, [...] com alguma discussão. Isso são momentos marcantes prá nós (entrevista com Ipê Amarelo, 2011).

Há uma espécie de saudosismo nessas narrativas. Saudades de um tempo em que diziam que todos (ou quase todos) se agregavam em torno de objetivos comuns. Saudades da cumplicidade e de um tempo em que eram mais jovens. Saudades de uma Faculdade que é percebida como ícone do envolvimento com as greves. As pessoas constroem um passado que as legitime. Fica o que significa. Essa comunidade afetiva 
preferiu falar daquilo que considera "bonito", como diz uma das professoras, evidenciando os laços que os uniam naqueles momentos de solidariedade e congraçamento por uma luta que era de todos.

\section{Palavras finais}

“Narrativas de memória são narrativas de identidade" (Errante, 2000), assim, entende-se o quanto as memórias desses sujeitos, professores da FACED, assumem o tom autobiográfico, em que se estreitam as relações entre memória e sentimento de identidade. "A memória é um elemento constituinte do sentimento de identidade, tanto individual como coletiva, na medida em que ela é também um fator extremamente importante do sentimento de continuidade e de coerência de uma pessoa ou de um grupo em sua reconstrução de si." (Pollak, 1992, p.204).

As memórias da Faculdade de Educação da UFRGS, produzidas pelas lembranças e esquecimentos dos sujeitos que a construíram como espaço pioneiro de formação docente no RS, se entrelaçam às trajetórias do ensino superior brasileiro. A FACED, enquanto unidade de ensino recebeu diferentes influências na sua constituição. $O$ cenário nacional do final da década de 1960 apontava para a busca do desenvolvimento e o investimento no ensino universitário parecia o caminho adequado para a obtenção de profissionais que elevariam a qualidade técnica brasileira. Deste modo, relatórios foram escritos por assessores estrangeiros que indicaram as diretrizes políticas e técnicas para uma reformulação do sistema educacional, com base nas supostas necessidades observadas. Os Acordos MEC-USAID foram, então, decisivos para a realização da Reforma Universitária e normatizações educacionais realizadas durante a ditadura militar brasileira.

As narrativas dos professores entrevistados nos remetem à insegurança que existia ao ministrar uma aula, escrever uma tese ou, simplesmente, conversar nos corredores da faculdade. Até mesmo as contratações de novos docentes foram dificultadas por conta do momento político vivido. Por meio desses exemplos, é possível pensarmos nas muitas implicações da ditadura militar na Faculdade de Educação. 
Halbwachs (2004, p.150) explica a importância do "quadro espacial" para as memórias coletivas. Vale enfatizar o quanto esse grupo de docentes construiu vínculos com o seu lugar de trabalho, segundo o autor mencionado, "é sobre o nosso espaço aquele que ocupamos e que nosso pensamento é a cada momento capaz de reconstruir é sobre ele que nosso pensamento deve se fixar, para que reapareça esta ou aquela categoria de lembranças". Sendo "o espaço é uma realidade que dura", então aquele prédio que por si só se constitui em um evocador de memórias, agrega esses docentes que, há muitos anos, para lá se dirigem, vão para as salas de aula, para suas salas de pesquisas e lá convivem com outras gerações, com alunos de diversos cursos de licenciatura.

De alguma forma, aqueles elos que uniam os docentes no passado, quando ressentiam-se da presença dos governos militares e depois nas lutas pelas melhorias no ensino superior público, ainda se manifestam, talvez de forma mais sutil, mas não menos evidente. Os laços que os aproximavam estão presentes ainda hoje, pois a FACED continua sendo um espaço de muitos embates políticos pela educação que se desdobram em diferentes nuances.

A FACED, com seus quarenta e dois anos, se transforma e mantém a posição de vanguarda no contexto da UFRGS. Atualmente promove debates e ações em prol das lutas políticas e educacionais que envolvem a educação do campo, comunidades quilombolas, povos indígenas, educação de jovens e adultos, juventudes, mulheres, infância, entre tantos outros temas discutidos. A FACED, criada em tempos de poder dos militares, tendo interferência direta do pensamento educacional estadunidense, hoje, é entendida como espaço de pluralidades, de estudo, de acolhimento às diferenças e, assim, busca ampliar cada vez mais suas relações com a sociedade em que se insere. Entende-se que as lutas enfrentadas pela Faculdade no início da redemocratização, a partir de meados dos anos 1980, promoveram a constituição da Faculdade que hoje conhecemos.

Por fim, cabe afirmar a relevância desse estudo para a história da FACED. Com base nas memórias evocadas, é possível refletir sobre fragmentos de seu cotidiano evidenciados nas decisões tomadas, representações construídas e ações que 
repercutiram na educação do Rio Grande do Sul. Trata-se de memórias de uma instituição educacional e da vida dos atores envolvidos que podem gerar novos estudos sobre a educação no Rio Grande do Sul. Produziram-se, também, fontes para a História da Educação, possibilitando maior visibilidade à história dessa instituição e ao percurso dos sujeitos que fizeram e fazem a FACED.

\section{Referências}

ALVES, Márcio Moreira. Beabá dos MEC-Usaid. Rio de Janeiro, Gernasa, 1968. Disponível em: <http://www.marciomoreiraalves.com/livro.1968beaba.htm>. Acesso em: 09 maio 2012.

BORDAS, Merion Campos; ANDREOLA, Balduíno Antonio. Os quarenta anos da Faculdade de Educação da UFRGS. Educação e Realidade, maio/agosto, 2010, v.35, n. 2, Porto Alegre. Disponível em: <http://seer.ufrgs.br/educacaoerealidade/issue/view/1081/showToc>. Acesso em: 28 maio 2012.

BRASIL. Conselho Federal de Educação. Parecer 977 de 1965. Brasil, DF. 1965. Disponível em: <http://www.scielo.br/scielo.php?pid=S1413-24782005000300014\&script=sci_arttext >. Acesso em: 17 jun. 2012.

BRASIL. Congresso Nacional. Lei 12.528 de 18 de novembro de 2011. Brasil, DF. 2011. Disponível em: http://www.planalto.gov.br/ccivil_03/_Ato2011-2014/2011/Lei/L12528.htm. Acesso em: 12 jun. 2012.

BRASIL. Congresso Nacional. Lei Federal n 4.464 de 9 de novembro de 1969. Brasil, DF. Disponível em: <http://www.gedm.ifcs.ufrj.br/upload/legislacao/357.pdf>. Acesso em: 17 jun. 2012.

BRUNETTO, Giancarla Miranda. Condor. Documentário, Porto Alegre/ RS, UFRGS, 2008. 29 $\min$.

COSTA, Bianca Silva - O ensino superior na ditadura militar brasileira: um olhar através da "Revista MEC". Dissertação (Mestrado). Pontifícia Universidade Católica do Rio Grande do Sul. Curso de Pós-Graduação em História da Faculdade de Filosofia e Ciências Humanas. Porto Alegre, 2009. Disponível em: <http://bdtd.ibict.br/. Acesso em: 22 mai. 2012>. Acesso em: 20 jun. 2012. 
CUNHA, Maria Teresa Santos. Nas margens do instituído: Memória/Educação. Revista da Educação. ASPHE/FaE/UFPel. Pelotas (5), jan.jun., v. 3, n. 5, p. 39-46, 1999.

DOLL, Johannes; COMERLATO, Denise. Editorial. Educação \& Realidade. Porto Alegre, v. 35, n. 2, maio/ago. 2010, p. 05-08. Disponível em: <http://seer.ufrgs.br/educacaoerealidade/article/view/15858/9440>. Acesso em: 17 jun. 2012.

ERRANTE, Antoinette. Mas afinal, a memória é de quem? histórias orais e modos de lembrar e contar. História da Educação. v. 4- n. 8, p. 141 - 174. Pelotas: UFPel. Setembro, 2000.

FÁVERO, Maria de Lourdes de Albuquerque. A Universidade no Brasil: das origens à Reforma Universitária de 1968. Educar, Curitiba, n. 28, p.17-36. 2006.. Editora UFPR Disponível em: <http://www.scielo.br/pdf/er/n28/a03n28.pdf>. Acesso em: 12 jun. 2012.

HALBWACHS, Maurice. A memória coletiva. São Paulo: Centauro, 2004.

LOPES, Eliane Marta; GALVÃO, Ana Maria de Oliveira. Território plural: a pesquisa em História da Educação. São Paulo: Ática, 2010.

MANSAN, Jaime Valim. Os expurgos na UFRGS: afastamentos sumários de professores no contexto da Ditadura Civil-Militar (1964 e 1969) Dissertação (mestrado) - Pontifícia Universidade Católica do Rio Grande do Sul. Curso de Pós-Graduação em História da Faculdade de Filosofia e Ciências Humanas. 2009. Disponível em: <http://www.dominiopublico.gov.br/pesquisa/DetalheObraForm.do?select_action=\&co_o bra $=137298>$. Acesso em: 28 maio 2012.

PESAVENTO, Sandra Jatahy. História e história cultural. Belo Horizonte: Autêntica, 2003.

POLLAK, Michael. Memória e identidade social. Estudos Históricos, Rio de Janeiro, v. 5, n.10, p. 200-212 1992.

PRINS, Gwyn. História Oral. BURKE, Peter (org.). A escrita da História: novas perspectives. São Paulo, Editora da Universidade Estadual Paulista, 1992, p. 163 a 198.

RANCIÉRE, Jacques. Sobre a história das mulheres no século XIX. In: DUBY, George; PERROT, Michelle. As mulheres e a história. Lisboa:Rolo \& Filhos Artes Gráficas, 1995.

RODEGHERO, Carla Simone; GUAZZELLI, Eloar; DIENSTMANN, Gabriel. Não calo, grito: memória visual da ditadura civil-militar no Rio Grande do Sul. 1. ed. Porto Alegre: Tomo Editorial, 2013. v. 1, 256p . 
VERHINE, Robert E. Pós-graduação no Brasil e nos Estados Unidos: uma análise comparativa. Educação, Porto Alegre, v. 31, n. 2, p. 166-172, maio/ago. 2008. Disponível em: <http://redalyc.uaemex.mx/src/inicio/ArtPdfRed.jsp?iCve=84819177006 >. Acesso em: 17 jun. 2012.

VIÑAO-FRAGO, Antonio. A modo de prologo, refugios del yo, refugio de outros. In. MIGNOT, Ana; BASTOS, Maria Helena Camara e CUNHA, Maria Teresa Santos (orgs.) Refúgios do Eu: educação, história e escrita autobiográfica. Florianópolis: Mulheres, 2000.

UFRGS. Faculdade de Educação. Programa PERICAMPUS: integração universidade/comunidades de Periferia Urbana - Proposta de ação para 1986. Porto Alegre, 1986.

UFRGS JORNAL DA UNIVERSIDADE. Encarte Especial: dos porões da história. Porto Alegre, ano XIII, n. 123, nov. 2009. Disponível em:

<http://www.ufrgs.br/comunicacaosocial/jornaldauniversidade/123/encarteze3.htm>. Acesso em 22 maio 2012.

ZAGO, Nadir. A entrevista e seu processo de construção: reflexões com base na experiência prática de pesquisa. In: ZAGO, Nadir; CARVALHO, Marília Pinto de VILELA, Rita Amélia Teixeira (orgs.) Itinerários de pesquisa: perspectivas qualitativas em sociologia de educação. Rio de Janeiro: DP\&A, 2003, p. 287-309. 